\title{
The Plantaris Muscle Tendon and Its Relationship with the Achilles Tendinopathy
}

\author{
L. Olewnik $\left(\mathbb{D},{ }^{1}\right.$ G. Wysiadecki ${ }^{D},{ }^{1}$ M. Podgórski, ${ }^{2}$ M. Polguj ${ }^{(D)},{ }^{3}$ and M. Topol ${ }^{1}$ \\ ${ }^{1}$ Department of Normal and Clinical Anatomy, Medical University of Lodz, Poland \\ ${ }^{2}$ Department of Diagnostic Imaging, Polish Mother's Memorial Hospital Research Institute, Lodz, Poland \\ ${ }^{3}$ Department of Angiology, Medical University of Lodz, Poland
}

Correspondence should be addressed to Ł. Olewnik; lukasz.olewnik@umed.lodz.pl

Received 19 February 2018; Accepted 30 April 2018; Published 31 May 2018

Academic Editor: Nihal Apaydin

Copyright (C) 2018 Ł. Olewnik et al. This is an open access article distributed under the Creative Commons Attribution License, which permits unrestricted use, distribution, and reproduction in any medium, provided the original work is properly cited.

\begin{abstract}
Purpose. Although the plantaris muscle (PM) is vestigial in humans, it has a significant clinical role in procedures such as grafting. However, recent reports suggest its potential involvement in the tendinopathy of the midportion of the Achilles tendon. The aim of the study is therefore to evaluate morphological variation of the PM with regard to its potential conflict with the Achilles tendon. Material and Methods. Classical anatomical dissection was performed on 130 lower limbs (71 right, 59 left) fixed in 10\% formalin solution. The morphology of the PM was assessed regarding the relationship between the course of the plantaris tendon and the calcaneal tendon. Results. The PM was present in $89.2 \%$ of cases. The findings indicate the presence of a new type of PM tendon insertion in which the tendon is inserted into the tarsal canal flexor retinaculum, potentially affecting the tendinopathy of the tibialis posterior muscle. In 26 cases (22.4\%), insertion blended with the Achilles tendon (Type II), which may increase the risk of Achilles tendinopathy. Conclusion. The anatomical variation of PM tendon morphology may create a potential conflict with the Achilles tendon and the tibialis posterior tendon, thus increasing the possibility of tendinopathy.
\end{abstract}

\section{Introduction}

The plantaris muscle (PM) is typically characterized by a short, slim, and spindle-shaped muscle belly and long tendon [1-3]. The origin of the muscle is located on the popliteal surface of the femur above the lateral condyle and on the knee joint capsule [1]. The length of the muscle belly ranges from 50 to $100 \mathrm{~mm}$ and it is located between the popliteal muscle and the lateral head of the gastrocnemius muscle [1-3]. As it runs towards the medial crural region, the muscle belly becomes a long tendon. In its initial course, the tendon is located between the gastrocnemius muscle (GM) and soleus muscle (SM) [2-4], and upon leaving this section, in its distal course, the plantaris tendon is typically inserted into the calcaneal tendon [1]. Despite this classical schema, the course of the PM tendon, and especially its insertion, is characterized by high morphological variability $[2,5-9]$. The plantaris muscle can be double $[1,10]$, and, in rare cases, it can be absent $[3,11-13]$.

An important clinical problem in recent years is Achilles tendon tendinopathy (ATT), which is difficult to cure $[2,3$,
14]. Although ATT affects both physically active and inactive patients, it is more often associated with running or jumping disciplines [15, 16]: ATT is observed most commonly in runners (ultramarathons), tennis players, volleyball players, and football players. Despite recent advances, the pathogenesis of this disease remains not fully understood [15-18]. Recent years have seen an increase in interest in the possible involvement of the plantaris tendon in Achilles tendinopathy, and it is believed that the course of this tendon may affect the development of ATT $[2,3,6-8,16,19]$.

The purpose of this study was to determine the anatomical relationship between the course of the plantaris tendon and the calcaneal tendon with regard to potential conflict associated with the tendons resulting in tendinopathy.

\section{Material and Methods}

In total, 130 lower limbs fixed in $10 \%$ formalin solution (71 right, 59 left) were obtained from adult cadavers. Consent 


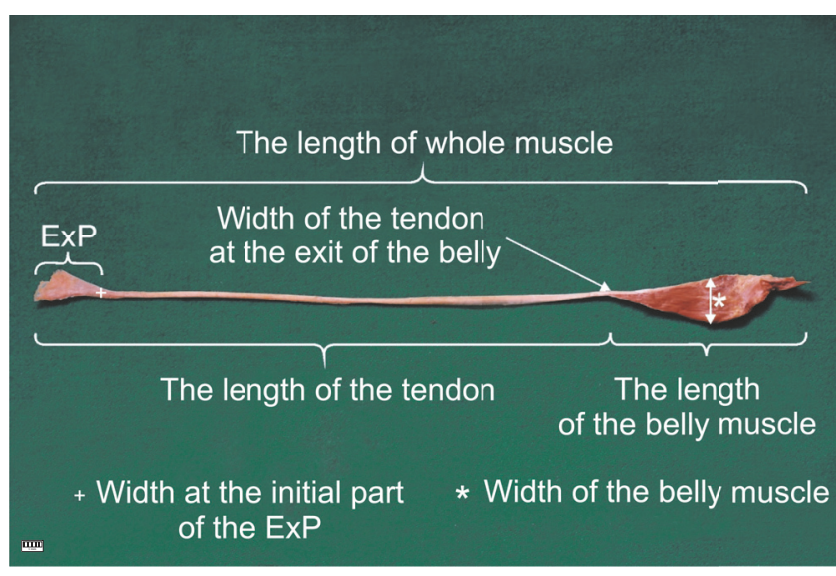

FIGURE 1: The basic measurements of the plantaris muscle.

for the study was given by the Local Bioethics Commission (agreement no. RNN/297/17/KE).

A dissection of the crural region and foot area was performed using traditional techniques [2, 3, 20]. Upon dissection, the following morphological features of the PM were assessed:

(i) Relationship between the course of the plantaris tendon and the calcaneal tendon

(ii) The location of the insertion of the plantaris tendon muscle

(iii) Morphometric measurements (Figure 1)

(iv) The characteristics of the extension point (ExP) [3] (width, thickness and distance between this point and the insertion of the plantaris tendon). ExP is the point at which the distal tendon begins to expand before its insertion [Figure 1]

An electronic digital caliper was used for all measurements (Mitutoyo Corporation, Kawasaki-shi, Kanagawa, Japan). Each measurement was carried out twice with an accuracy of up to $0.1 \mathrm{~mm}$.

\section{Statistical Analysis}

The statistical analysis was performed using Statistica 12 software (StatSoft Polska, Cracow, Poland). A $p$ value below 0.05 was considered significant. The results are presented as mean and standard deviation unless otherwise stated. The $\mathrm{Chi}^{2}$ test was used to compare the presence of PM between sexes and body sides. Continuous data was checked for normality with the Shapiro-Wilk test. As the data was not normally distributed, the Mann-Whitney $U$ test was then used to compare the anthropometric measurements between the two types of PM course. The types of PM insertion were compared with regard to ExPs dimensions using the KruskalWillis ANOVA with dedicated post hoc tests. The correlation of continuous variables was assessed with Spearman's rank correlation coefficient.

\section{Results}

Our present findings serve as an extension and addition to the classification of previous study [3].

4.1. Frequency of Occurrence of the Plantaris Muscle. The PM was present in 116 lower limbs (89.2\%) and absent on 14 limbs (10.8\%). Although the absence of a PM is sometimes indicative that the muscle has become fused with the gastrocnemius or soleus muscle, no such condition was observed in the present sample.

The PM occurred in $51(89.5 \%)$ men and 65 (89\%) women, and in $64(90.1 \%)$ cases on the right and $52(88.1 \%)$ on the left limbs. Differences in occurrence between sexes and body sides were not statistically significant $(p=0.8367$ and $p=$ 0.9338 , respectively).

4.2. Evaluation of Insertion of the Plantaris Tendon. The PM insertion was examined morphologically and classified according to the fivefold classification of Olewnik at al. [3].

(i) Type I (51 cases, 44\%) was characterized by a wide, fan-shaped insertion to the calcaneal tuberosity on the medial side of the calcaneal tendon (Figures 2(a) and 2(b)).

(ii) Type II (26 cases, 22.4\%) was characterized by insertion to the calcaneal tuberosity on the medial side, along with the Achilles tendon of the PT which was beaded in common parathendon with the calcaneal tendon (Figures 2(c) and 2(d)).

(iii) Type III ( 8 cases, $6.9 \%$ ) was characterized by insertion at the calcaneal bone, anterior to the calcaneal tendon (from 0.9 to $2.3 \mathrm{~mm}$; Figures 3(a) and 3(b)).

(iv) Type IV (4 cases, 3.4\%) was characterized by the insertion to the deep crural fascia; the insertion was not located in the calcaneal bone. The PT has no direct "communication" with the calcaneal tendon, and the PT runs 2.3 to $2.4 \mathrm{~mm}$ anterior to it (Figures $3(\mathrm{c}$ ) and $3(\mathrm{~d})$ ).

(v) Type V (21 cases, 18.1\%) was characterized by a very wide insertion encircling the posterior and medial surfaces of the calcaneal tendon (Figures 4(a) and $4(\mathrm{~b}))$.

Additionally, six cases (5.2\%) presented a type of insertion that has not been described before: one characterized with insertion at a point near to the tarsal canal flexor retinaculum of the leg (Figures 4(c) and 4(d)). This is proposed as a new Type VI. Table 1 presents the morphological characteristics of ExPs in particular types of PM insertion.

The width of the ExP differed significantly between types of PM insertion $(p<0.0001)$ with Type I being significantly wider than Types II and VI; Type II being significantly narrower than Types I, IV and V; and Type VI being significantly narrower than Types I and V. The distance between the ExP and the PM insertion point also differed significantly $(p=0.0145)$, so that insertion was significantly closer to the calcaneus in Type VI than in Types IV and V. The thickness of the ExP did not differ significantly $(p=0.0524)$. 


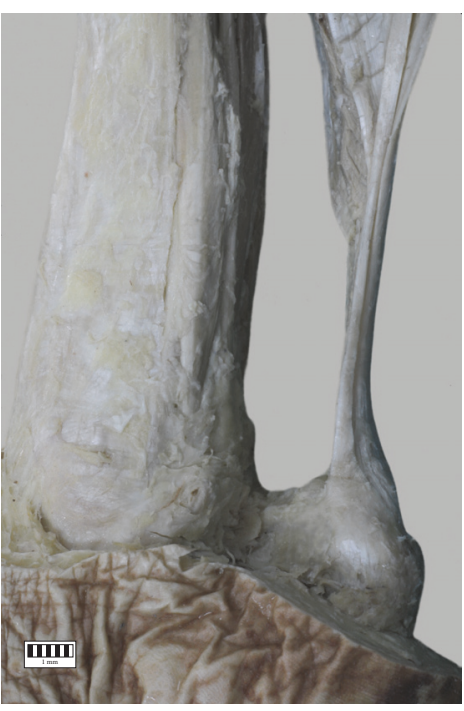

(a)

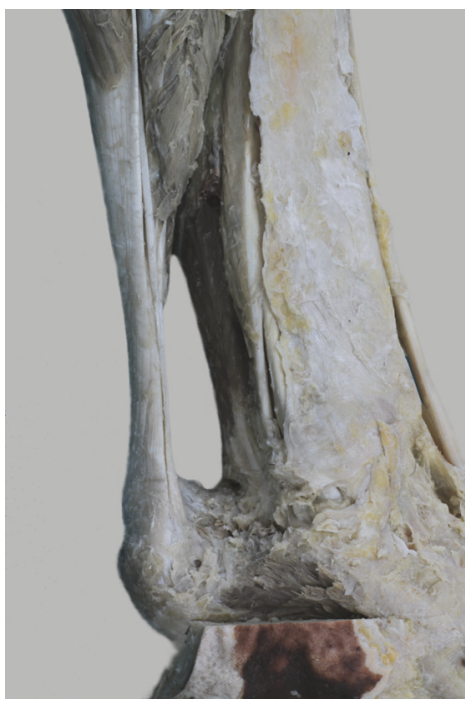

(c)

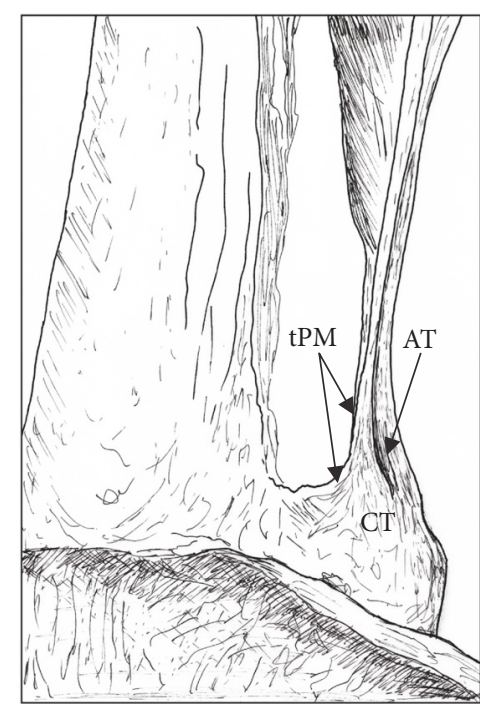

(b)

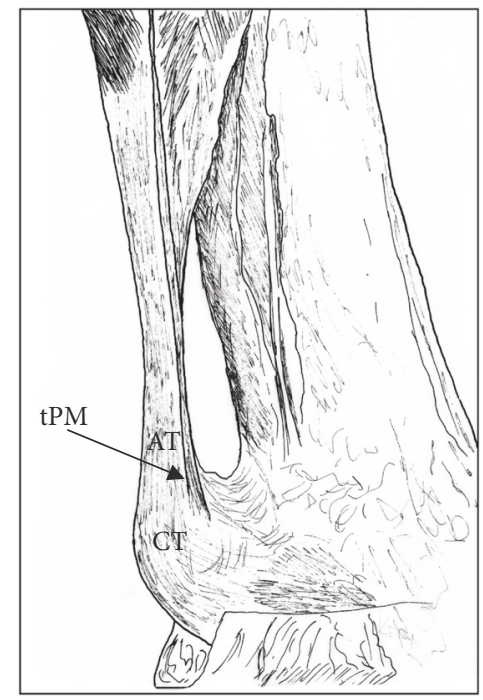

(d)

FIGURE 2: Types of insertion of the plantaris tendon: (a) Type I of insertion of plantaris tendon, (b) schema of Type I insertion (tPM: plantaris muscle tendon, AT: Achilles tendon, and CT: calcaneal tuberosity), (c) Type II plantaris tendon, and (d) schema of Type II insertion (PT: plantaris tendon, tPM: plantaris muscle tendon, AT: Achilles tendon, and CT: calcaneal tuberosity).

TABLE 1: Morphological characteristics of ExP in different types of PM insertion.

\begin{tabular}{lccc}
\hline PM tendon type $(n)$ & $\begin{array}{c}\text { Tendon width at the ExP } \\
\text { mean (range) [mm] }\end{array}$ & $\begin{array}{c}\text { Tendon thickness at the ExP } \\
\text { mean (range) [mm] }\end{array}$ & $\begin{array}{c}\text { Distance between ExP and insertion } \\
\text { mean (range) [mm] }\end{array}$ \\
\hline Type I (51) & $3.73(2.21-6.82)$ & $1.22(0.32-2.45)$ & $34.33(12.05-87.43)$ \\
Type II (26) & $2.18(1.12-4.05)$ & $0.89(0.37-1.73)$ & $33.09(10.26-61.51)$ \\
Type II (8) & $2.74(2.12-4.74)$ & $1.27(0.74-1.69)$ & $38.67(8.33-53.42)$ \\
Type IV (4) & $4.06(2.84-4.88)$ & $0.72(0.46-1.04)$ & $54.26(41.22-73.09)$ \\
Type V (21) & $3.80(2.19-6.12)$ & $0.88(0.32-1.29)$ & $40.24(20.89-49.68)$ \\
Type VI (6) & $2.17(1.27-3.21)$ & $1.04(0.46-1.76)$ & $22.53(18.69-33.21)$ \\
\hline
\end{tabular}

PM: plantaris muscle; ExP: extension point. 


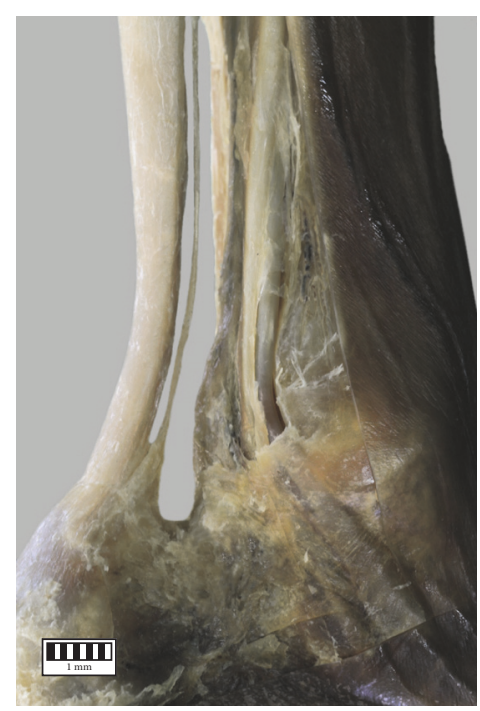

(a)

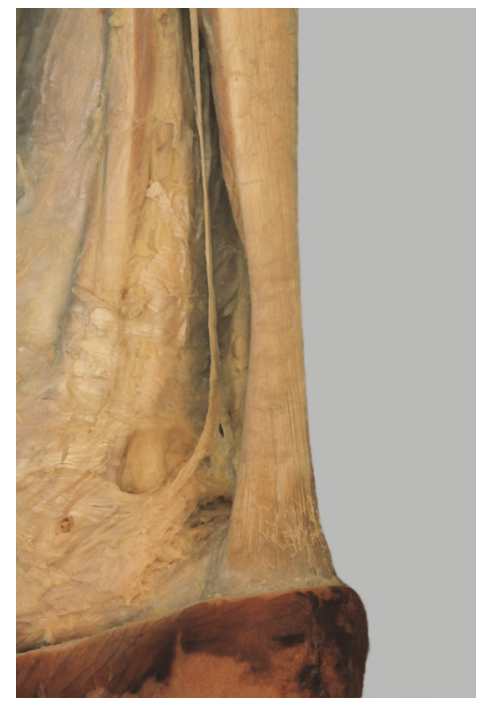

(c)

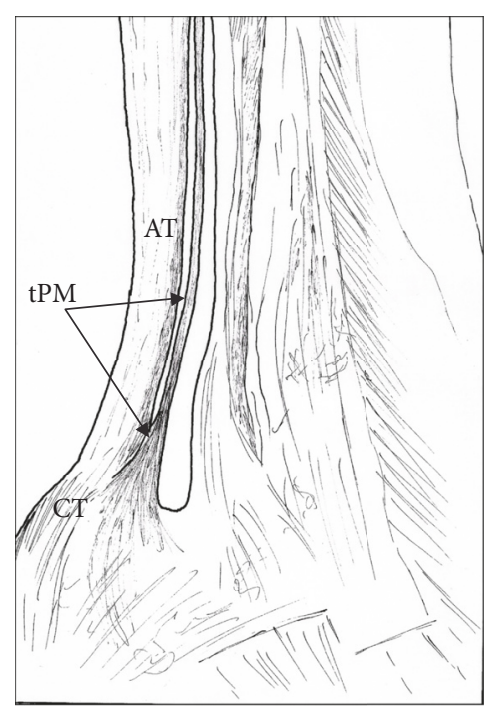

(b)

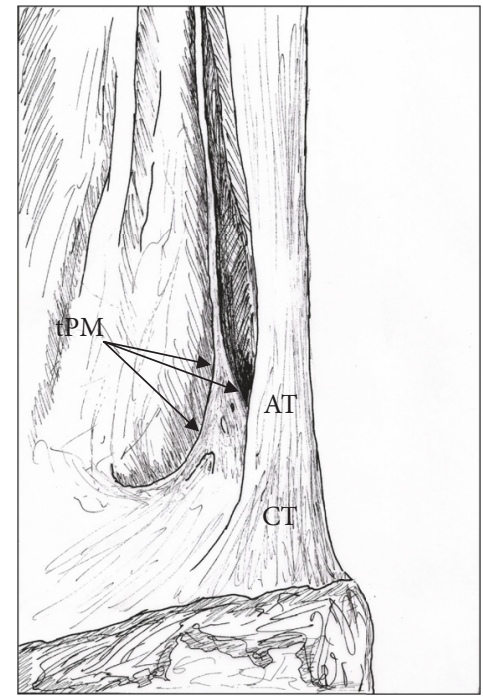

(d)

Figure 3: Types of insertion of the plantaris tendon: (a) Type III of insertion of plantaris tendon, (b) schema of the Type III of insertion (PT: plantaris tendon, tPM: plantaris muscle tendon, AT: Achilles tendon, and CT: calcaneal tuberosity), (c) Type IV of insertion of plantaris tendon, and (d) schema of the Type IV of insertion (PT: plantaris tendon, tPM: plantaris muscle tendon, AT: Achilles tendon, and CT: calcaneal tuberosity).

\subsection{Evaluation of Variants of the Course of the Plantaris} Tendon in relation to the Calcaneal Tendon. The course of the plantaris tendon was classified into two variants based on Olewnik et al. [3].

In variant A (98 cases, $84.5 \%$ ), the tendon was initially the space between the gastrocnemius muscle and soleus muscle (Figure 5) and then ran to the medial part of the leg; it was located on the medial side of the calcaneal tendon (Figure 6(a)).

In variant B (18 cases, $15.5 \%)$, the initial course resembled that of variant A; however, upon leaving the space between the GM and SM, it turned towards the medial crural
TABLE 2: Dependence between the insertion type and the plantaris tendon course variant.

\begin{tabular}{lc}
\hline $\begin{array}{l}\text { Plantaris tendon } \\
\text { course variant }\end{array}$ & $\begin{array}{c}\text { Type of insertion of } \\
\text { plantaris tendon }\end{array}$ \\
\hline A & I, II, V \\
B & III, IV, VI \\
\hline
\end{tabular}

region and ran directly anterior to the calcaneal tendon (Figure 6(b)). The characteristics of these two variants with regard to intention type are presented in Tables 2 and 3. 


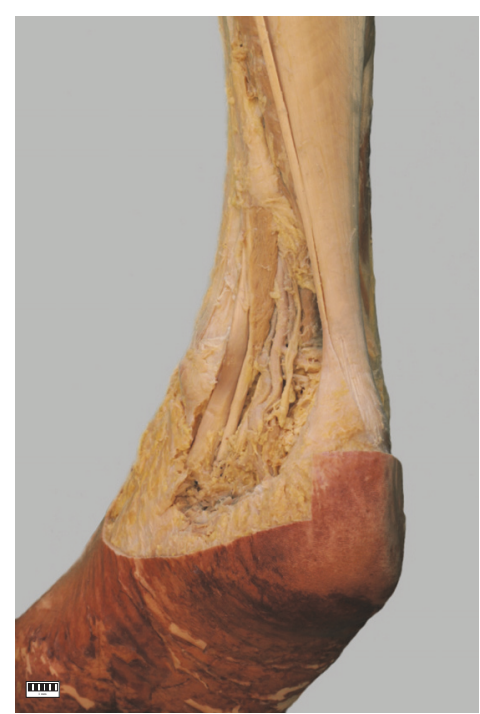

(a)

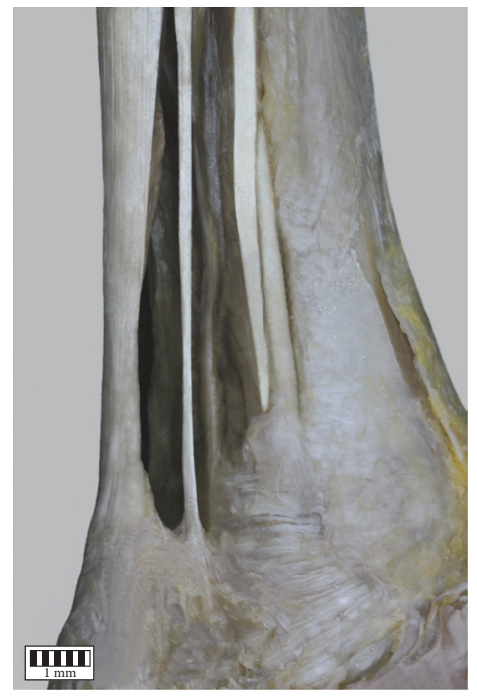

(c)

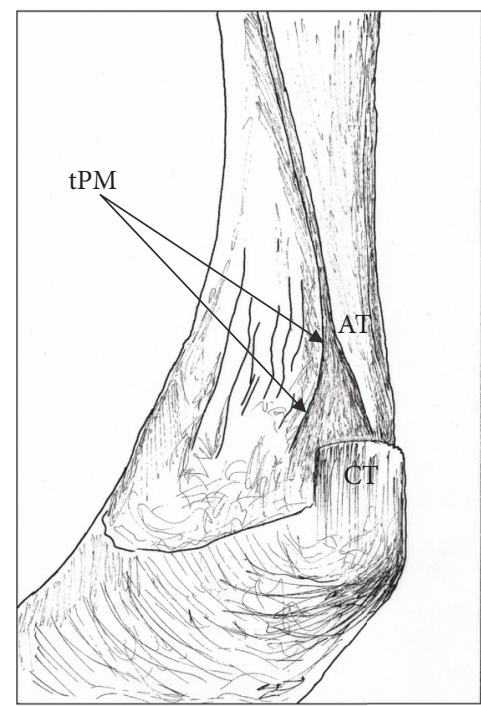

(b)

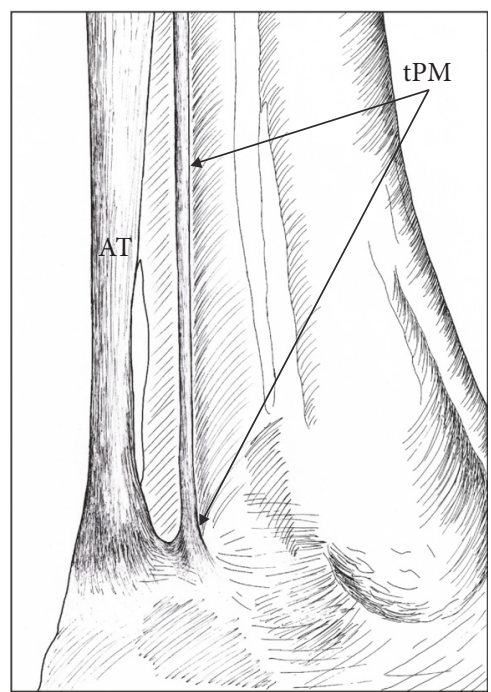

(d)

FIgure 4: Types of insertion of the plantaris tendon: (a) Type V of insertion of the plantaris tendon, (b) schema of the Type V of insertion of the plantaris tendon muscle tPM tendon of plantaris muscle AT Achilles tendon CT calcaneal tuberosity, (c) Type VI of insertion of the plantaris tendon muscle, and (d) schema of the Type VI of insertion of the plantaris tendon tPM tendon of plantaris muscle AT Achilles tendon CT calcaneal tuberosity.

TABLE 3: Correlation between body side, gender and course variant of the PT.

\begin{tabular}{|c|c|c|c|}
\hline & $\begin{array}{c}\text { Right lower limb }(n=64) \\
\text { COURSE VARIANT OF THE PLANTARIS TENDON }\end{array}$ & Left lower limb $(n=52)$ & $p$ value \\
\hline Variant A $[n(\%$ null $)]$ & $55(47.4)$ & $43(37.1)$ & \multirow{2}{*}{0.8241} \\
\hline \multirow[t]{3}{*}{ Variant B $[n(\%$ null $)]$} & $9(7.8)$ & $9(7.8)$ & \\
\hline & Men $(n=51)$ & Women $(n=65)$ & \multirow{2}{*}{$p$ value } \\
\hline & COURSE VARIANT OF THE PLANTARIS TENDON & & \\
\hline Variant A $[n(\%$ null $)]$ & $43(37.1)$ & $55(47.4)$ & \multirow{2}{*}{0.8307} \\
\hline Variant B $[n(\%$ null $)]$ & $8(6.9)$ & $10(8.6)$ & \\
\hline
\end{tabular}


TABLE 4: The differences between classifications given in the present study and those of other authors.

\begin{tabular}{|c|c|c|c|c|c|}
\hline Types of insertion of the PtM & $\begin{array}{c}\text { Cummins et al. } \\
{[\%]}\end{array}$ & $\begin{array}{c}\text { Nayak et al. } \\
{[\%]}\end{array}$ & $\begin{array}{c}\text { van Sterkenburg et al. } \\
{[\%]}\end{array}$ & $\begin{array}{l}\text { Olewnik et al. } \\
{[\%]}\end{array}$ & $\begin{array}{c}\text { Present } \\
{[\%]}\end{array}$ \\
\hline $\begin{array}{l}\text { Fan-shaped insertion into the medial calcaneal } \\
\text { tuberosity }\end{array}$ & 47 & - & 24 & 44 & 44 \\
\hline $\begin{array}{l}\text { To the calcaneus, occurring } 0.5-2.5 \mathrm{~cm} \text { anterior to the } \\
\text { medial boarder of the calcaneal tendon }\end{array}$ & 36.5 & - & 1.8 & 8 & 6.9 \\
\hline $\begin{array}{l}\text { Broad insertion investing the posteriori and medial } \\
\text { surfaces on the adjacent distal calcaneal tendon }\end{array}$ & 12.5 & - & 15 & 22 & 18.1 \\
\hline $\begin{array}{l}\text { Insertion into the medial border of the calcaneal } \\
\text { tendon at a level } 1-16 \mathrm{~cm} \text { proximal point at which the } \\
\text { calcaneal tendon }\end{array}$ & 4 & - & - & - & - \\
\hline $\begin{array}{l}\text { insertion to the calcaneal tuberosity on the medial side, } \\
\text { along with the Achilles tendon of the PT was in beaded } \\
\text { in common parathendon with the calcaneal tendon }\end{array}$ & - & - & - & 18 & 22.4 \\
\hline Insertion to the deep fascia & - & - & 0.9 & 4 & 3.4 \\
\hline Insertion to the flexor retinaculum of the leg & - & 28.8 & - & - & 5.2 \\
\hline Medial onto calcaneus & - & - & 20 & - & - \\
\hline Medial onto calcaneal tendon & - & - & 2.8 & - & - \\
\hline Medial with thin slips onto calcaneus & - & - & 4.7 & - & - \\
\hline Anteromedial onto calcaneus & - & - & 14 & - & - \\
\hline Anteromedial fan-shaped onto calcaneus & - & - & 17 & - & - \\
\hline To the os calcaneus & - & 36.5 & - & - & - \\
\hline To the calcaneal tendon at varus level & - & 26.9 & - & - & - \\
\hline
\end{tabular}

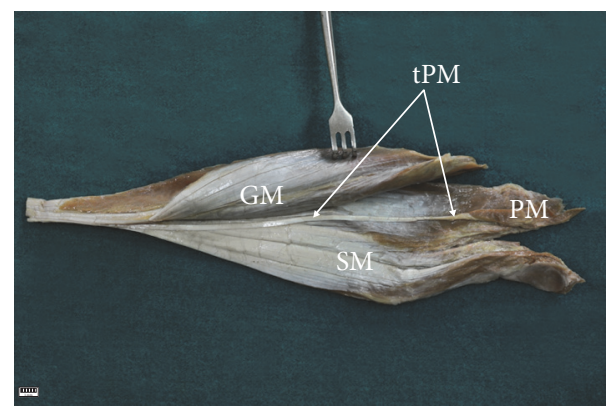

Figure 5: The space of the gastrocnemius muscle and soleus muscle. tPM tendon of the plantaris muscle PM plantaris muscle GM gastrocnemius muscle SM soleus muscle.

\section{Discussion}

Increasing numbers of Achilles tendon disorders, including tendinopathy, are being recorded [21-25]. The midportion of the tendon is most commonly affected, accounting for $55-65 \%$ of Achilles tendon related pathologies, followed by insertional tendinopathy, accounting for 20-25\% [23-26]. Midportion Achilles tendinopathy is very difficult to treat and its mechanism is not completely understood $[2,3,6-$ $9,19,25,26]$.

Recent years have seen an increase in the number of studies on PM and its potential involvement in midportion Achilles tendinopathy [2, 3, 6-8, 16, 25-27].
Five types of insertion and two variants of PT course have previously been recognised [3]. Our findings extend this classification with Type VI, this being a PT that is inserted into the flexor retinaculum of the leg, and show that the individual types of insertion significantly differed from each other. Insertion classifications, including the one proposed in the present study, are presented in Table 4.

Interestingly, neither Cummins and Anson [27] nor Van Sterkenburg et al. [7] report the possibility of insertion to the flexor retinaculum of the leg: on rare occasions, this area is susceptible to tendinopathy and dislocation of the tibialis posterior muscle $[28,29]$. It should be considered whether this type of insertion can predispose the patient to tendinopathy or dislocation of the tibialis posterior tendon.

Alfredson and Spang [25] note that Achilles midportion tendinopathy is more likely to affect men $(65 \%)$ than women (35\%). In addition, they found that, in $41 \%$ of patients, the plantaris tendon was located close to the medial side of the midportion of the Achilles tendon $[9,25]$. In addition, van Sterkenburg et al. [8] note that the close connection between the calcaneal tendon and plantaris tendon was located at the level of the Achilles midportion tendinopathy. Alfredson [6] noted that patients complain of pain located between 2 and $7 \mathrm{~cm}$ above the calcaneal tuberosity on the medial side.

The findings of these anatomical and clinical studies suggest that the type of insertion and the course of the PM tendon can affect the occurrence of midportion tendinopathy. Variant A of tendon course and Type II of its insertion may predispose a patient to this condition, because the PT is 


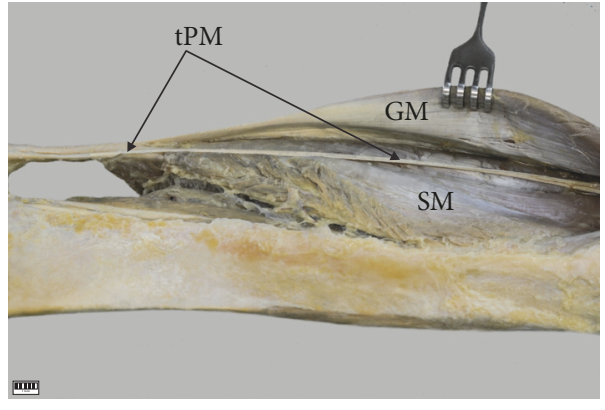

(a)

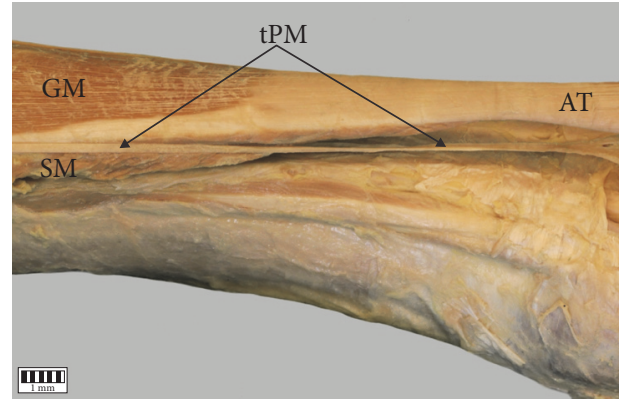

(b)

FIgURE 6: The variable anatomical correlation of the plantaris tendon. (a) Variant I of the plantaris tendon course. (b) Variant II of the plantaris tendon course. The plantaris tendon. GM gastrocnemius muscle, SM soleus muscle, and PT plantaris tendon.

beaded with common parathendon with Achilles tendon. Moreover, although it seems less probable, Types I, V, and VI, which are in close contact with the Achilles tendon, may also irritate/compress the Achilles tendon predisposing to tendinopathy.

In the present study, the PM was found to be absent in 14 lower limbs $(10.8 \%)$. In these cases, the limb was carefully examined to confirm whether the PM had fused with the surrounding muscles. Harvey et al. [30] observed absence of the PM in 19\% of cases, and Nayak et al. [31] in $7.69 \%$. Simpson et al. [11] found this muscle to be absent between 7 and $20 \%$ of cases. Nevertheless, not all authors reported such an absence: Van Sterkenburg et al. [7] and Aragão et al. [12] note no cases of plantaris muscle absence, which begs the question of whether a lack of PM can have a significant effect on Achilles tendon tendinopathy. In our opinion, it cannot influence midportion Achilles tendinopathy, because there is no possibility of a relationship existing between variant A of PT course and Type II insertion. However, as PM tendon involvement is not fully understood, more clinical studies are required.

Ultrasound and colour Doppler examination have yielded reliable diagnoses of pathology within the calcaneal tendon and have proven valuable in evaluating morphological variation in this region $[25,32,33]$. As the rupture of the plantaris tendon may cause symptoms similar to deep vein thrombosis [13], ultrasound with a colour Doppler option seems to be the first line choice in planning surgery and diagnosing ruptures or deep vein thrombosis.

A limitation of this study is that it only speculates on the potential consequences of particular anatomical variants of PM tendon course and insertion. Nevertheless, it may serve as a starting point for further clinical studies including those including patients with tendinopathy.

\section{Conclusion}

Our findings indicate the presence of a new type of PM tendon insertion (Type VI) with a different potential role in tibialis posterior conflict. The course of the plantaris tendon and type of insertion may have a significant effect on the onset of Achilles midportion tendinopathy.

\section{Data Availability}

Please contact authors for data requests (Ph.D. Ł. Olewnik, email address: lukasz.olewnik@umed.lodz.pl).

\section{Ethical Approval}

The protocol of the study was accepted by Bioethics Committee of Medical University of Lodz (resolution RNN/297/17/KE). The cadavers belong to the Department of Normal and Clinical Anatomy of the Medical University of Lodz. The Local Bioethics Commission issued a consent for the study (agreement no. RNN/297/17/KE). This article does not contain any studies with human participants or animals performed by any of the authors.

\section{Disclosure}

Authors have no financial or personal relationship with any third party whose interests could be positively or negatively influenced by the article's content. This research did not receive any specific grant from funding agencies in the public, commercial, or not-for-profit sectors.

\section{Conflicts of Interest}

The authors declare that they have no conflicts of interest.

\section{Authors' Contributions}

Ł. Olewnik was responsible for project development, data collection and management, data analysis, and manuscript writing. G. Wysiadecki was responsible for data collection and manuscript editing. M. Podgórski and Professor M. Polguj were responsible for data collection, data analysis, and manuscript editing. M. Topol was responsible for data analysis and manuscript editing. All authors have read and approved the manuscript.

\section{Acknowledgments}

The authors wish to express their gratitude to all those who donated their bodies to medical science. 


\section{References}

[1] R. A. Bergman, A. K. Afifi, and R. Miyauchi, "Anatomy Atlases: Illustrated Encyclopedia of Human Anatomic VariationAnatomical Variation-Radiology Anatomy-Anatomy Atlas," http://www.anatomyatlases.org/AnatomicVariants/AnatomyHP .shtml.

[2] Ł. Olewnik, G. Wysiadecki, M. Polguj, and M. Topol, "The report on the co-occurrence of two different rare anatomic variations of the plantaris muscle tendon on both sides of an individual," Folia Morphologica (Poland), vol. 76, no. 2, pp. 331333, 2017.

[3] Ł. Olewnik, G. Wysiadecki, M. Polguj, and M. Topol, "Anatomic study suggests that the morphology of the plantaris tendon may be related to Achilles tendonitis," Surgical and Radiologic Anatomy, vol. 39, no. 1, pp. 69-75, 2017.

[4] A. A. Spina, "The plantaris muscle: anatomy, injury, imaging, and treatment," The Journal of the Canadian Chiropractic Association, vol. 51, no. 3, pp. 158-165, 2007.

[5] S. R. Nayak, A. Krishnamurthy, L. V. Prabhu, and S. Madhyastha, "Additional tendinous origin and entrapment of the plantaris muscle," Clinics, vol. 64, no. 1, pp. 67-68, 2009.

[6] H. Alfredson, "Midportion Achilles tendinosis and the plantaris tendon," British Journal of Sports Medicine, vol. 45, no. 13, pp. 1023-1025, 2011.

[7] M. N. Van Sterkenburg, G. M. M. J. Kerkhoffs, R. P. Kleipool, and C. Niek Van Dijk, "The plantaris tendon and a potential role in mid-portion Achilles tendinopathy: An observational anatomical study," Journal of Anatomy, vol. 218, no. 3, pp. 336341, 2011.

[8] M. N. van Sterkenburg, G. M. M. J. Kerkhoffs, and C. N. van Dijk, "Good outcome after stripping the plantaris tendon in patients with chronic mid-portion Achilles tendinopathy," Knee Surgery, Sports Traumatology, Arthroscopy, vol. 19, no. 8, pp. 1362-1366, 2011.

[9] J. Smith, H. Alfredson, L. Masci, J. L. Sellon, and C. D. Woods, "Differential plantaris-achilles tendon motion: a sonographic and cadaveric investigation," PM\&R: The Journal of Injury, Function, and Rehabilitation, vol. 9, no. 7, pp. 691-698, 2017.

[10] K. K. Rana, S. Das, and R. Verma, "Double plantaris muscle: A cadaveric study with clinical importance," International Journal of Morphology, vol. 24, no. 3, pp. 495-498, 2006.

[11] S. L. Simpson, M. S. Hertzog, and R. H. Barja, "The plantaris tendon graft: An ultrasound study," Journal of Hand Surgery, vol. 16, no. 4, pp. 708-711, 1991.

[12] J. A. Aragão, F. P. Reis, D. R. Guerra, and R. H. Cabral, "The occurrence of the plantaris muscle and its muscle-tendon relationship in adult human," International Journal of Morphology, vol. 28, no. 1, pp. 255-258, 2010.

[13] D. M. Kwinter, J. P. Lagrew, J. Kretzer et al., "Unilateral double plantaris muscle: A rare anatomical variation," International Journal of Morphology, vol. 28, no. 4, pp. 1097-1099, 2010.

[14] H. Mao, Z. Shi, K. L. Wapner, W. Dong, W. Yin, and D. Xu, "Anatomical study for flexor hallucis longus tendon transfer in treatment of Achilles tendinopathy," Surgical and Radiologic Anatomy, vol. 37, no. 6, pp. 639-647, 2015.

[15] L. Masci, "Is tendinopathy research at a crossroads?" British Journal of Sports Medicine, vol. 49, no. 16, pp. 1030-1031, 2015.

[16] L. Masci, C. Spang, H. T. M. Van Schie, and H. Alfredson, "How to diagnose plantaris tendon involvement in midportion Achilles tendinopathy - Clinical and imaging findings," BMC Musculoskeletal Disorders, vol. 17, no. 1, article 97, 2016.
[17] J. L. Cook, K. M. Khan, and C. Purdam, "Achilles tendinopathy," Manual Therapy, vol. 7, no. 3, pp. 121-130, 2002.

[18] J. L. Cook and C. R. Purdam, "Is tendon pathology a continuum? A pathology model to explain the clinical presentation of load-induced tendinopathy," British Journal of Sports Medicine, vol. 43, no. 6, pp. 409-416, 2009.

[19] H. Alfredson, "Ultrasound and Doppler-guided mini-surgery to treat midportion Achilles tendinosis: Results of a large material and a randomised study comparing two scraping techniques," British Journal of Sports Medicine, vol. 45, no. 5, pp. 407-410, 2011.

[20] Ł. Olewnik, M. Podgórski, M. Polguj, G. Wysiadecki, and M. Topol, "Anatomical variations of the pronator teres muscle in a Central European population and its clinical significance," Anatomical Science International, pp. 1-8, 2017.

[21] M. Kvist, "Achilles tendon injuries in athletes," Sports Medicine, vol. 18, no. 3, pp. 173-201, 1994.

[22] T. A. H. Järvinen, P. Kannus, M. Paavola, T. L. N. Järvinen, L. Józsa, and M. Järvinen, "Achilles tendon injuries," Current Opinion in Rheumatology, vol. 13, no. 2, pp. 150-155, 2001.

[23] S. De Jonge, C. Van Den Berg, R. J. De Vos et al., "Incidence of midportion Achilles tendinopathy in the general population," British Journal of Sports Medicine, vol. 45, no. 13, pp. 1026-1028, 2011.

[24] C. A. Asplund and T. M. Best, "Achilles tendon disorders," British Medical Journal, vol. 346, article f1262, 2013.

[25] H. Alfredson and C. Spang, "Clinical presentation and surgical management of chronic Achilles tendon disorders - A retrospective observation on a set of consecutive patients being operated by the same orthopedic surgeon," Journal of Foot and Ankle Surgery, 2017.

[26] C. Spang, H. Alfredson, M. Ferguson, B. Roos, J. Bagge, and S. Forsgren, "The plantaris tendon in association with midportion achilles tendinosis - Tendinosis-like morphological features and presence of a non-neuronal cholinergic system," Histology and Histopathology, vol. 28, no. 5, pp. 623-632, 2013.

[27] E. J. Cummins and B. J. Anson, "The structure of the calcaneal tendon (of Achilles) in relation to orthopedic surgery, with additional observations on the plantaris muscle," Surgery, Gynecology \& Obstetrics, vol. 83, pp. 107-116, 1946.

[28] N. R. Goucher, M. J. Coughlin, and R. M. Kristensen, "Dislocation of the posterior tibial tendon: a literature review and presentation of two cases," The Iowa Orthopaedic Journal, vol. 26, pp. 122-126, 2006.

[29] A. Ortolani, R. Bevoni, A. Russo, M. Marcacci, and M. Girolami, "Posterior tibial tendon displacement behind the tibia and its interposition in an irreducible isolated ankle dislocation: A case report and literature review," Joints, vol. 4, no. 3, pp. 183-188, 2016.

[30] F. J. Harvey, G. Chu, and P. M. Harvey, "Surgical availability of the plantaris tendon," Journal of Hand Surgery, vol. 8, no. 3, pp. 243-247, 1983.

[31] S. R. Nayak, A. Krishnamurthy, L. Ramanathan et al., "Anatomy of plantaris muscle: A study in adult Indians," La Clinica Terapeutica, vol. 161, no. 3, pp. 249-252, 2010.

[32] M. Paavola, T. Paakkala, P. Kannus, and M. Järvinen, "Ultrasonography in the differential diagnosis of achilles tendon injuries and related disorders: a comparison between preoperative ultrasonography and surgical findings," Acta Radiologica, vol. 39, no. 6, pp. 612-619, 1998. 
[33] L. Öhberg, R. Lorentzon, and H. Alfredson, "Neovascularisation in Achilles tendons with painful tendinosis but not in normal tendons: An ultrasonographic investigation," Knee Surgery, Sports Traumatology, Arthroscopy, vol. 9, no. 4, pp. 233$238,2001$. 


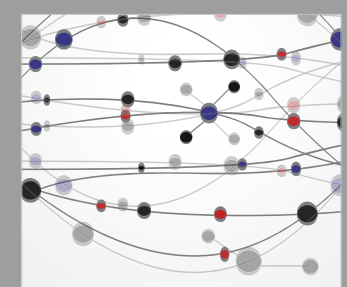

The Scientific World Journal
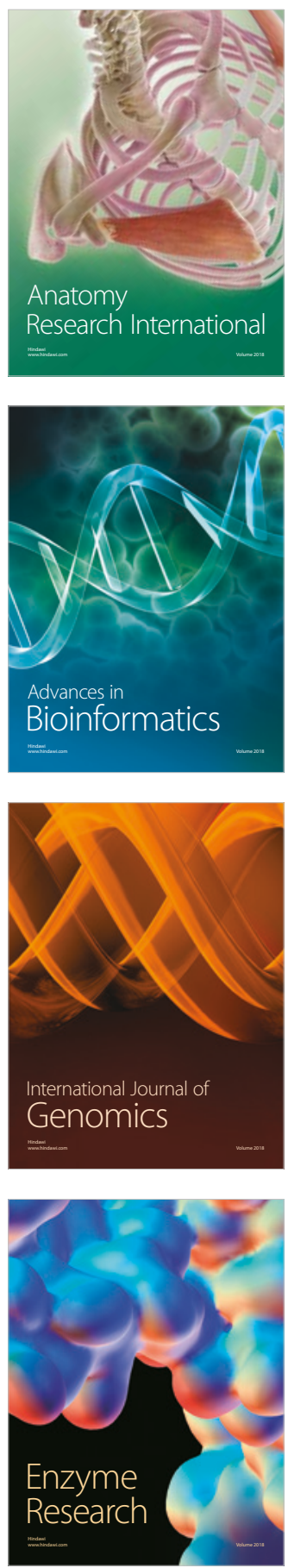
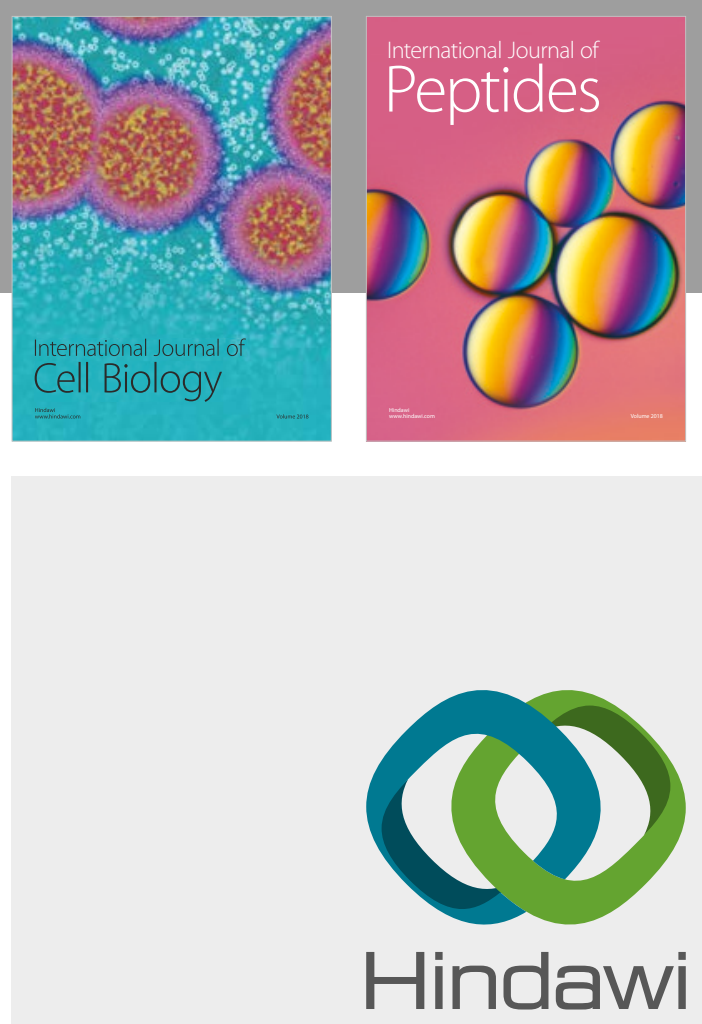

Submit your manuscripts at

www.hindawi.com
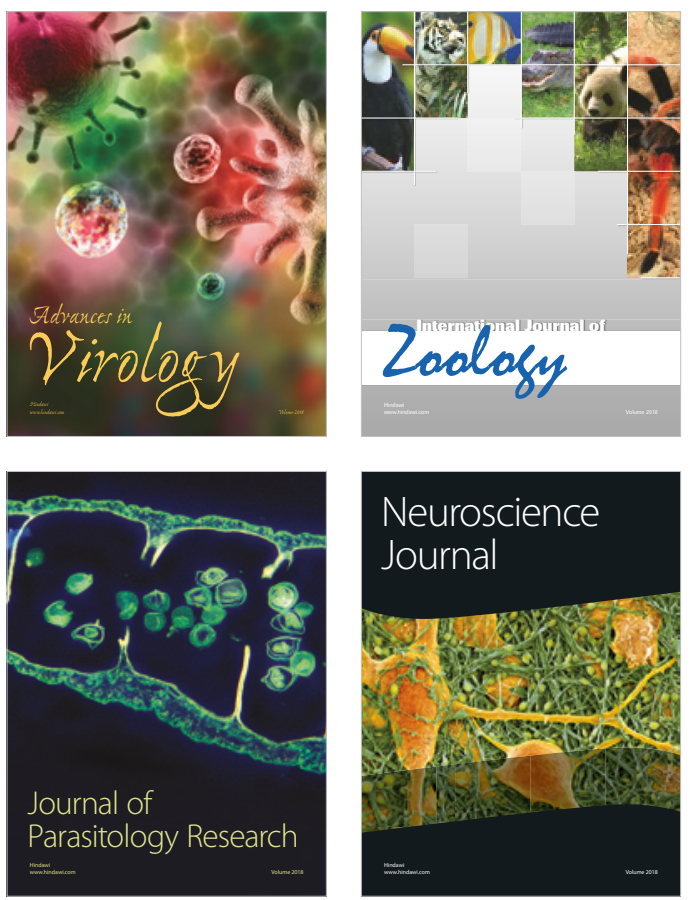
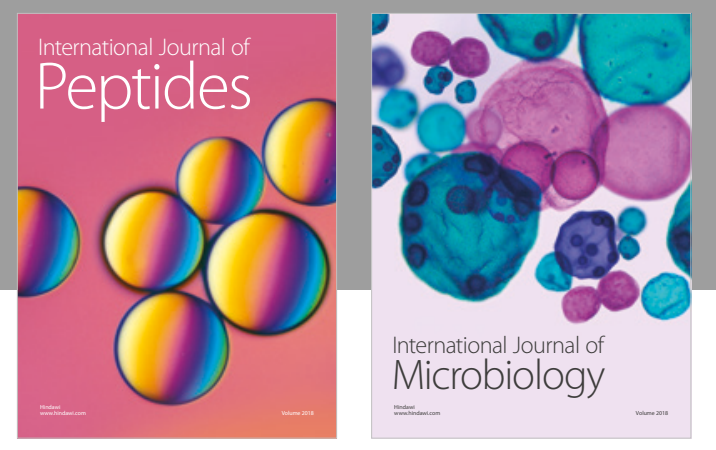

nternational Journal of Microbiology
Journal of
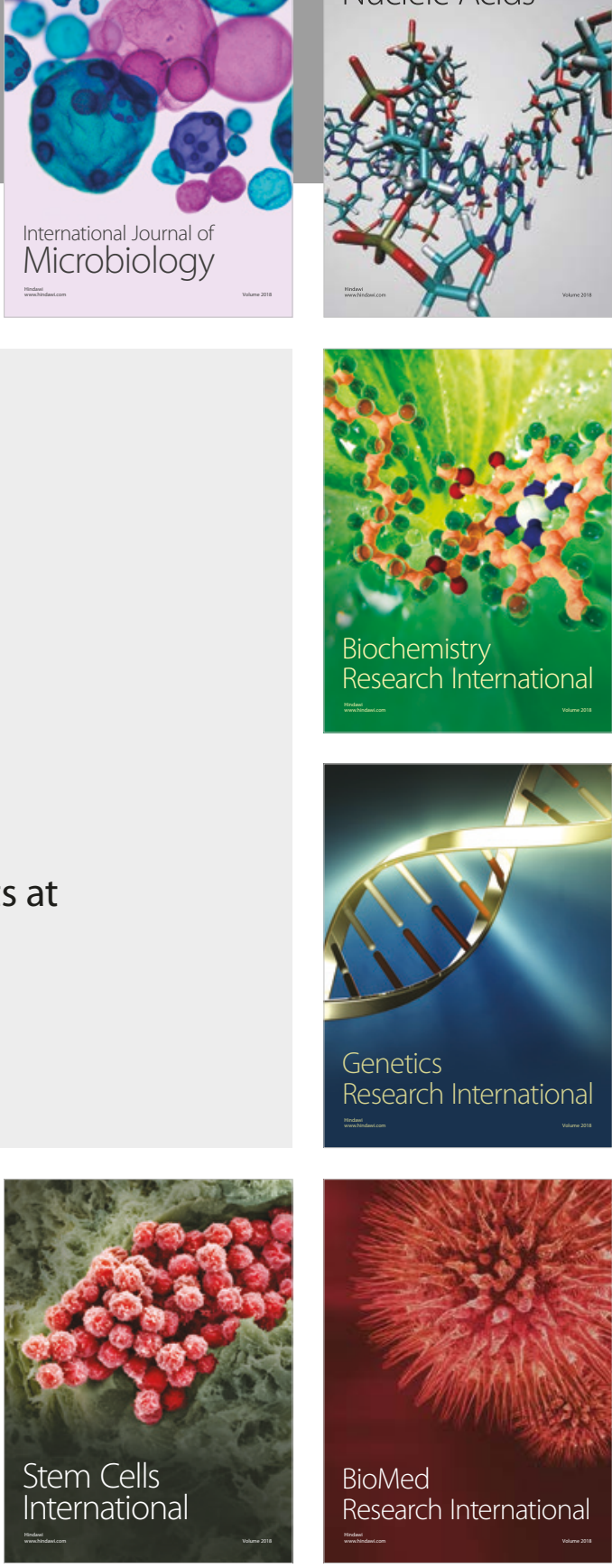
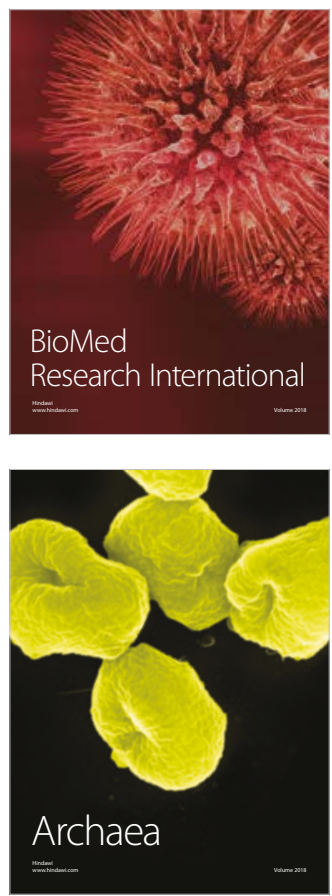